\title{
М.Э. Чумакина
}

\section{Университет графства Суррей,} GU7 2XH г. Гилфорд, Великобритания

\section{Атрибутив в арчинском языке}

В статье рассматривается категория атрибутива в арчинском языке (нахскодагестанская семья). При отсутствии прилагательного как самостоятельной части речи, в арчинском языке выделяется атрибутив - класс форм, регулярно образующихся от четырех основных частей речи: существительных, глаголов, наречий и послелогов. Синтаксически атрибутив выполняет роль прилагательного, т.е. служит определением к существительному и выполняет роль присвязочного элемента в именном сказуемом. Атрибутив в арчинском языке обладает своей собственной согласовательной парадигмой и одновременно сохраняет морфосинтаксические свойства производящего слова. Это позволяет охарактеризовать арчинский атрибутив, с одной стороны, как представителя типологически известной категории «смешанного» класса словоформ (mixed category), а с другой - как редкое явление формально обособленного класса производных слов, регулярно образующихся от всех имеющихся в языке частей речи.

Ключевые слова: нахско-дагестанские языки, арчинский язык, морфосинтаксис, смешанные категории, прилагательное.

DOI: 10.31862/2500-2953-2018-4-166-189

\section{Chumakina}

\section{University of Surrey,} Guildford, GU7 2XH, United Kingdom

\section{Attributive in Archi}

In this paper I discuss attributive in Archi (Nakh-Daghestanian). Archi lacks an independent category of adjective and uses attributives instead. Attributives in Archi belong to a transpositional mixed category that can be formed from any of the four main parts of speech: nouns, verbs, ad verbs and postpositions. Based 
on a detailed analysis of their syntactic and morphological properties, I demonstrated that Archi attributives retain some of the morphosyntactic characteristics of their base category, whilst simultaneously having morphological and syntactic characteristics shared across transposed forms. At the same time, it can be shown that Archi attributives have a unique distribution and agreement pattern that is clearly distinct from any other lexical class. All these make Archi attributive simultaneously possess both morphological and syntactic characteristics of two syntactic categories.

Key words: Nakh-Daghestanian languages, Archi language, morphosyntactic features, mixed categories, adjective.

\section{1. Введение}

В настоящей статье рассматриваются атрибутивные формы арчинского языка и их место в грамматической системе. Используя семантические и формальные признаки, в арчинском языке легко выделить следующие части речи: существительное, глагол, наречие и послелог. Первые два класса обладают чрезвычайно богатым словоизменением. Категория же прилагательного как самостоятельной части речи в арчинском языке отсутствует (не считая небольшого закрытого класса неизменяемых слов, о котором речь пойдет в разд. 3.4).

В роли определения к существительному, а также в роли присвязочного элемента именного сказуемого выступает атрибутив - форма, которую невозможно ни отнести к какой-либо из частей речи, упомянутых выше, ни выделить в самостоятельную часть речи: регулярно образуясь от существительных, глаголов, наречий и послелогов, атрибутивы, во-первых, имеют прозрачную деривативную структуру, а во-вторых, сохраняют некоторые морфосинтаксические свойства производящего слова, распадаясь таким образом на четыре класса: отыменные, отглагольные, отнаречные и отпослеложные атрибутивы.

Вместе с тем, атрибутивы обладают уникальной согласовательной парадигмой, отличающей их от всех остальных частей речи, и представляют собой, таким образом, особый морфосинтаксический класс.

Атрибутив в арчинском языке образуется путем прибавления суффикса -t:u (с алломорфами - $d u$ и -nnu) к основе (или полной словоформе), относящейся к одной из четырех самостоятельных частей речи. Так, в примере (1) неизменяемый стативный глагол $n a^{\varsigma} \zeta$ 'быть незрелым' маркирован атрибутивным суффиксом - $d u$. За атрибутивным суффиксом следует маркер согласования по роду и числу. Согласование контролируется либо вершиной именной группы, как в примере (1), либо подлежащим, когда атрибутивная форма выступает в роли именного сказуемого, как показано в примере (2): 
(1) na $a^{\mathrm{S}} \mathrm{-}-\mathrm{du}-\mathrm{b}$ быть.незрелым-ATTR-III.SG 'незрелый абрикос' axbəzan

абрикос(III)[SG.ABS]
(2) axbəzan абрикос(III)[SG.ABS] 'Абрикос был незрелым.' na's-du-b

быть.незрелым-ATTR-III.SG $\mathrm{e}<\mathrm{b}\rangle \mathrm{di}$

〈III.SG〉быть.PST

Суффикс -t:u-CM${ }^{1}$ регулярно присоединяется ко всем лексемам всех частей речи и в этом смысле ведет себя скорее как словоизменительный, чем как словообразовательный маркер [Haspelmath, 1996], с поправкой на транскатегориальность. В примерах (1) и (2) показано образование атрибутива от стативного глагола, в примере (3) - от динамического глагола, в примере (4) - от существительного.

(3) $w-e^{e}\langle r\rangle \breve{s}: u-r-t: u$ bošor

I.SG-〈IPFV〉бежать-IPFV-ATTR[I.SG] мужчина(I)[SG.ABS]

'бегущий мужчина'

(4) or $\chi^{\mathrm{q} i-l i-n-n u-t}$

diq' соль(IV)-SG.OBL-GEN-ATTR-IV.SG 'соленый суп'

суп(IV)[SG.ABS]

В разд. 2 приводятся общие сведения о грамматическом строе арчинского языка, необходимые для дальнейшего обсуждения атрибутива. Атрибутив является особой категорией, обладающей собственной согласовательной парадигмой и синтаксическими свойствами. Эти свойства можно назвать «внешними» свойствами атрибутива. Они обсуждаются в разд. 3 .

В то же время атрибутив сохраняет определенные морфосинтаксические свойства производящего слова: вид, согласование и управление глагола, падежное маркирование существительного, управление послелога. Эти свойства можно назвать «внутренними» свойствами атрибутива, и они обсуждаются в разд. 4. Выводы прелдставлены в разд. 5.

\section{2. Арчинский язык, общие сведения}

На арчинском языке говорит около 1200 человек, проживающих в селении Арчи ${ }^{2}$ Чародинского района Республики Дагестан. Арчи состоит из шести хуторов, находящихся в пределах пешей доступности. По многим параметрам арчинский язык является типичным

\footnotetext{
${ }^{1} \mathrm{CM}$ - согласовательный маркер.

${ }^{2}$ В научной традиции село носит название Арчи. Сами жители в русской речи используют название Арчиб - аваризованный вариант лакского слова [Архипов et al., 2008].
} 
представителем нахско-дагестанской семьи: это эргативный язык с базовым порядком слов SOV, с четко определяемыми частями речи и богатой словоизменительной морфологией.

В арчинском языке выделяется четыре рода существительных ${ }^{3}$. Принадлежность существительного к тому или иному роду определяется семантически для рода I и II (лица мужского и женского пола соответственно). Принадлежность же к роду III и IV исходя из семантики можно предсказать только приблизительно: в целом, одушевленные существительные относятся к роду III, а неодушевленные - к роду IV, но это верно далеко не для всех существительных.

Существительное выступает в роли контролера согласования, мишенью же согласования может быть любая другая часть речи: позиция для согласования имеется у большинства простых динамических глаголов, у нескольких наречий, в нескольких формах местоимений, у одного послелога и у всех атрибутивов [Chumakina, Corbett, 2015; Bond et al., 2016]. В табл. 1 представлены морфологические показатели согласования на глаголе.

Таблица 1

Префиксальные и инфиксальные показатели рода на глаголе

\begin{tabular}{|c|c|c|c|}
\hline \multirow{2}{*}{\multicolumn{2}{|c|}{ РОД }} & \multicolumn{2}{|c|}{ число } \\
\hline & & & \\
\hline I & Люди мужского пола & $w-/\langle w\rangle$ & \\
\hline II & Люди женского пола & $d-/\langle r\rangle$ & \\
\hline III & $\begin{array}{l}\text { Животные, насекомые, некоторые неодушевленные } \\
\text { предметы }\end{array}$ & $b-/\langle b\rangle$ & \\
\hline IV & $\begin{array}{l}\text { Предметы, некоторые животные, абстрактные } \\
\text { существительные }\end{array}$ & $\varnothing-/\langle\varnothing\rangle$ & \\
\hline
\end{tabular}

В единственном числе согласование различает все четыре рода, в то время как во множественном имеется только одно противопоставление: лица vs не лица. Согласовательная парадигма атрибутива имеет другую структуру: во-первых, у рода I нулевой показатель. Во-вторых, у рода IV имеется ненулевой показатель - $t$, и в-третьих, во множественном числе род не различается, но имеется показатель множественного

\footnotetext{
${ }^{3}$ В кавказоведческой традиции род существительных называется «классом». Я буду употреблять термин «род», поскольку типологически эта категория является именно грамматическим родом и ничем не отличается от грамматического рода в других языках (см. [Corbett, 1991]).
} 
числа, отличный от всех других форм (табл. 2), в то время как глагольные согласовательные показатели множественного числа формально совпадают с некоторыми показателями единственного.

Таблицьа 2

Суффиксальные показатели рода (класса) на атрибутивах

\begin{tabular}{|c|c|c|c|}
\hline \multirow{2}{*}{\multicolumn{2}{|c|}{ РОД }} & \multicolumn{2}{|c|}{ число } \\
\hline & & & \\
\hline I & Люди мужского пола & $-\varnothing$ & \\
\hline II & Люди женского пола & $-r$ & \\
\hline III & $\begin{array}{l}\text { Животные, насекомые, некоторые неодушевленные } \\
\text { предметы }\end{array}$ & $-b$ & $-i b$ \\
\hline IV & $\begin{array}{l}\text { Предметы, некоторые животные, абстрактные } \\
\text { существительные }\end{array}$ & $-\mathrm{t}$ & \\
\hline
\end{tabular}

У существительного имеется богатая падежная парадигма. Все падежи, кроме абсолютива, образуются от косвенной основы; падежи разделяются на грамматические и локативные, локативные падежи имеют двухчастную структуру: к косвенной основе сперва прибавляется суффикс локализации, а к нему - окончание направительного падежа (примеры см. 4.4).

Глаголы в арчинском языке делятся на динамические и стативные (подробнее см. 4.1.1). Ортогонально этому делению имеется деление глаголов на простые и сложные. Простые глаголы представляют собой закрытый класс, состоящий примерно из 170 лексем. Сложные глаголы состоят из неизменяемой лексический части и простого глагола. У глаголов имеется богатая словоизменительная парадигма, морфологически базирующаяся на четырех видовых основах (4.1.1), большой набор видо-временных категорий, несколько наклонений. Нефинитные формы глагола представлены конвербами, отглагольными существительными и атрибутивами.

Арчинский язык является морфологически эргативным, т.е. субъект переходного глагола кодируется эргативным падежом, а объект переходного глагола и субъект непереходного - абсолютивом:

(5) buwa-mu мать(II)-SG.ERG bo-kto III.SG-давать.PFV 'Мать дала нам этот абрикос.' a $b ə z a n$

b-el

ja-b

абрикос(III)[SG.ABS]

III.SG-1PL.DAT

эTOT-III.SG 
(6) zon

1.SG.ABS сейчас

d-eq ${ }^{\text {i }}$

'Я сейчас приду.'

Именная группа в абсолютиве контролирует все согласование в клаузе. Так, в примере (5) абсолютивная группа jab aұbəzan 'этот абрикос' контролирует согласование по роду (III) и числу (SG) на глаголе bokto 'дала' и на местоимении bel 'нам', выраженное приставками bo- и $b$ соответственно. В качестве вершины именной группы aхbəzan 'абрикос' контролирует согласование на всех своих зависимых, в данном случае - на указательном местоимении jab 'этот', где согласование выражается суффиксом - $b$. Вершина именной группы контролирует согласование на всех своих зависимых независимо от падежа, в котором стоит вершина.

Согласование непереходных глаголов также контролируется абсолютивом. В примере (6) абсолютивное местоимение zon 'я' контролирует согласование по роду (II) и числу (SG) на глаголе $d e q^{\varsigma_{i}}$ 'приду'. Здесь согласование контролируется родом референта местоимения, которым в данном случае является женщина.

Типичным для дагестанских языков является и маркирование в арчинском языке аргументов глаголов восприятия, эмоций, а также некоторых когнитивных глаголов: экспериенцер кодируется дательным падежом, а стимул - абсолютивом. В примере (7) это местоимение tuwmis 'ему' и существительное $A j \check{s} a$ (женское имя) соответственно. Как и в примерах (5) и (6), абсолютивный аргумент контролирует согласование на глаголе:
(7) tu-w-mi-s
Ajša
d-ak:u
TOT-I.SG-SG.OBL-DAT
Айша(II)[SG.ABS]
II.SG-видеть.PFV
'Он видел Айшу.'

\section{3. Внешние морфосинтаксические свойства атрибутива}

Внешние морфосинтаксические свойства атрибутивов являются общими для всех представителей этого класса, независимо от того, к какой части речи принадлежит производящее слово. Эти свойства включают способность служить определением к существительному (разд. 3.1) и выступать в роли предикативного присвязочного элемента (разд. 3.2). Парадигма согласования атрибутива отличает его от всех остальных частей речи (разд. 3.3), а его способность присоединять падежные окончания при безвершинном употреблении отличает атрибутив от небольшого закрытого класса неизменяемых прилагательных (разд. 3.4).

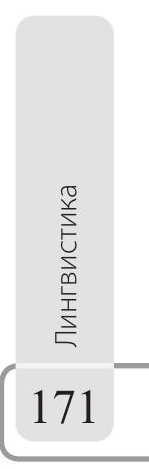




\section{1. Определение к существительному}

Атрибутивная группа может выступать в качестве определения к существительному независимо от того, к какой части речи принадлежит производящее слово. В примере (1) был представлен атрибутив, образованный от стативного глагола, в примере (3) - от динамического глагола, в примере (4) был представлен атрибутив от существительного. Пример (8) представляет атрибутив от еще одного стативного глагола, 'быть высоким':

(8) be: $\chi u-t: u$

быть.высоким-ATTR[I.SG] 'высокий парень' lo

парень(I)[SG.ABS]

Одно существительное может быть модифицировано несколькими атрибутивами. Так, в примере (9) два атрибутива соединены сочинительной частицей $-u$, присоединяющейся к каждому из членов сочинительной конструкции. Порядок сочиненных атрибутивов может варьировать, ср. (10):

(9) jamu-r hiba-t:u-r-u mu-t:u-r-u этоT-II.SG быть.хорошим-ATTR-II.SG-и быть.красивым-ATTR-II.SG-и lo d-i-kul-1-a

девушка(II)[SG.ABS] II.SG-быть.PRS-NMLZ-OBL-IN

'Так как она была хорошей и красивой девушкой...'

[Кибрик et al., 1977, с. 9]

(10) ja

$\begin{array}{ll}\text { jamu-r } & \text { mu-t:u-r-u } \\ \text { этот-II.SG } & \text { быть.красивым-ATTR-II.SG-AND } \\ \text { hiba-t:u-r-u } & \text { lo } \\ \text { быть.хорошим-ATTR-II.SG-AND } & \text { девушка(II)[SG.ABS] } \\ \text { d-i-kul-l-a } & \\ \text { II.SG-быть.PRS-NMLZ-OBL-IN } & \end{array}$

'Так как она была красивой и хорошей девушкой...'

В то же время, если существительное модифицировано атрибутивом и указательным местоимением, порядок определений поменять нельзя, ср. (11) и неграмматичный пример (12):

(11) jamu-t uq a-t:u-t s:a9al-li-t этоT-IV.SG приходить.PFV-ATTR-IV.SG время(IV)-SG.OBL-SUP $\mathrm{a}<\mathrm{b}>\mathrm{u}-\mathrm{li}$ dagawur 〈III.SG〉делать.PFV-EVID д договор(III)[SG.ABS] 'Когда он пришел (в это время его прихода), подписали договор.' 


$$
\begin{aligned}
& \text { (12) *uq a-t:u-t } \\
& \text { jamu-t s:aSal-li-t } \\
& \text { приходить.PFV-ATTR-IV.SG это-IV.SG время(IV)-SG.OBL-SUP } \\
& \mathrm{a}<\mathrm{b}>\mathrm{u}-\mathrm{li} \\
& \text { dagawur } \\
& \text { 〈III.SG〉делать.PFV-EVID д договор(III)[SG.ABS] } \\
& \text { *'Когда он пришел (в это время его прихода), } \\
& \text { подписали договор.' }
\end{aligned}
$$

Пример (11) иллюстрирует еще одно важное свойство согласования атрибутива в позиции определения: он согласуется с вершиной независимо от ее падежа. Сушествительное s:aSallit 'во время' стоит в локативном падеже (суперэссиве) и контролирует согласование атрибутива uq at:ut.

В конструкциях с числительными порядок числительное - атрибутив является предпочтительным, ср. пример (13), порядок же атрибутив числительное, представленный в примере (14), принимается не всеми говорящими ${ }^{4}$ :
(13) $\operatorname{lib}<t^{\prime}>\mathrm{u}$

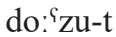 adam три 〈IV.SG〉 быть.большим.ATTR-IV.SG человек(IV)[SG.ABS] aču-li
[IV.SG] убивать.PFV-EVID
'Он убил трех взрослых (лит.: трех больших людей).'
? do: ${ }^{\text {' }} \mathrm{zu}-\mathrm{t}$
быть.большим.ATTR-IV.SG aču-li
lib $<t^{\prime}>\mathrm{u}$
adam
три〈IV.SG〉 человек(IV)[SG.ABS]
[IV.SG]убивать.PFV-EVID
?‘Он убил трех взрослых (лит.: трех больших людей).'

В арчинском языке есть еще один класс слов, которые могут выступать в качестве определения к существительному. Это так называемые неизменяемые прилагательные:
(15) o o ro $^{\varsigma} \mathrm{s} \quad$ lo
русский парень(I)[SG.ABS]
'русский парень'

Неизменяемые прилагательные представляют собой закрытый класс, включающий 26 лексем, обозначающих национальности (пример 16), качества (пример 17) и количество чего-либо (пример 18).

${ }^{4}$ Одна из наших консультантов считала порядок атрибутив - числительное в примеpe (14) грамматичным, в то время как ее сестра считала такой порядок недопустимым. 
(16) Национальности

aršat:en 'арчинский'

dargin 'даргинский'

haman 'лакский'

jat:an 'аварский'

пивај 'ногайский'

$o^{\uparrow} r{ }^{\uparrow} S$ 'русский'

parang 'французский'

pirs:i 'персидский'

Sarab 'арабский'

(17) Качества

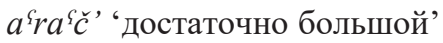

bišin 'чужой'

buraq' 'бронзовый'

but'u 'другой'

čere 'сухой'

čelennin 'частный, личный'

dalu 'сумасшедший'

ћok'o 'маленький'

hовоl 'спелый'

kulu 'сиротский'

t:enne 'женский'

maSarul 'горный'

mektle 'мужской'

nak'alaj 'старинный'

$w a^{\varsigma} p$ ' 'упитанный' (о младенцах)

(18) Количество

čeћ 'никакой'

no:q'ukan 'многие'

Неизменяемые прилагательные могут сочетаться друг с другом и с производными атрибутивами в порядке, подлежащем семантическим, но не структурным ограничениям. Так, примеры (19) и (20) показывают, что неизменяемое прилагательное $o^{\uparrow} r o^{\uparrow} S$ 'русский' может занимать 
позицию непосредственно перед определяемым существительным, но допустим и порядок, при котором между неизменяемым прилагательным и существительным-вершиной стоят атрибутивы.

\begin{tabular}{|c|c|c|}
\hline (19) & olo-ma-ši & $\mathrm{uq}^{\mathfrak{\complement} \mathrm{a}}$ \\
\hline & [IV.SG]1PL.GEN-CVB.LOC-ALL & I.SG.приходить.PFV \\
\hline & be: $\chi u-t: u$ & mu-t:u \\
\hline & быть.высоким-ATTR.I.SG & быть.красивым-ATTR.I.SG \\
\hline & $\mathrm{o}^{\complement} \mathrm{ro}^{\complement} \mathrm{s}$ & lo \\
\hline & русский & парень(I)[SG.ABS] \\
\hline & ‘К нам приехал высокий кр & Івый русский парень.' \\
\hline$(20)$ & olo-ma-ši & $\mathrm{uq}^{\complement} \mathrm{a}$ \\
\hline & [IV.SG]1PL.GEN-CVB.LOC-ALL & I.SG.приходить.PFV \\
\hline & $\mathrm{o}^{\complement} \mathrm{ro}^{\complement} \mathrm{s}$ & be: $\chi u-t: u$ \\
\hline & русский & быть.высоким-ATTR.I.SG \\
\hline & mu-t:u & lo \\
\hline & быть.красивым-ATTR.I.SG & парень(I)[SG.ABS] \\
\hline
\end{tabular}

Неизменяемые прилагательные могут быть модифицированы словами со значением степени. Так, в примере (21) pišt'an 'очень' модифицирует неизменяемое прилагательное, а в примере (22) - атрибутив.

(21) pišt'an

but'u

очень странный

'очень странный мужчина'

(22) pišt'an

be: $\chi u-t: u$

очень

быть.высоким-ATTR.I.SG

'очень высокий мужчина' bošor

мужчина(I)[SG.ABS]

В разд. 3.3 и 3.4 приводятся аргументы в пользу того, что неизменяемые прилагательные не являются подклассом атрибутивов (неизменяемыми атрибутивами), а должны быть выделены в отдельный класс.

\section{2. Присвязочный элемент}

Атрибутивы могут выступать в качестве присвязочного элемента в составе именного сказуемого. Так, в примере (23) атрибутив ұalat:ur 'старый' предшествует связке. В этом употреблении атрибутив входит в состав глагольной (предикативной) группы и подчиняется правилам согласования предикатов: согласуется с абсолютивом клаузы (абсолютив в роли определения согласуется с вершиной, которой необязательно иметь форму абсолютива). Морфологически согласование 
присвязочного атрибутива идентично согласованию атрибутива в функции определения. Так, если контролер согласования - именная группа рода II в форме единственного числа, согласовательным показателем атрибутива будет суффикс $-r$ независимо от того, к какой синтаксической категории относится контролер, является ли он абсолютивным аргументом клаузы (глагольное согласование) или же вершиной именной группы (именное согласование).

В примере (23) атрибутив и связка согласуются с абсолютивом zon 'я' по роду референта:

(23) zon

1SG.ABS быть.старым-ATTR-II.SG 'Я старая.' d-i

II.SGбыть.PRS

Неизменяемые прилагательные также могут выступать в позиции присвязочного элемента (24). Данный контекст позволяет разграничить неизменяемые прилагательные и стативные глаголы (которые на основании семантики можно считать классом прилагательных, см. [Гращенков, 2018]): стативный глагол может сам возглавлять клаузу, в то время как неизменяемому прилагательному требуется связка.
(24) zon
dargin
d-i
1sG.ABS даргинский
II.SG-быть.PRS
'Я даргинка (лит.: даргинская).'

Неизменяемые прилагательные в роли присвязочного элемента могут модифицироваться атрибутивами (25), что сближает их с существительными. Пример (26) показывает, что неизменяемое прилагательное в роли присвязочного элемента может быть модифицировано наречием степени, как и атрибутив (27).

(25) tu-w

mu-t:u

o ${ }^{\uparrow}$ ro $^{\varsigma} \mathrm{s}$ $\mathrm{W}-\mathrm{i}$

TоT-I.SG быть.красивым-ATTR.I.SG

русский

I.SG-быть.PRS

'Он - красивый русский.'

(26) tu-w

$$
\text { pišt'an }
$$

dalu

$\mathrm{W}-\mathrm{i}$

TOT-I.SG

очень

сумасшедший

I.SG-быть.PRS

'Он совершенно (досл.: очень) сумасшедший.'

(27) jamu-t

biq"

edi-li

этоT-IV.SG

lap

место(IV)[SG.ABS]

[IV.SG]быть.PST-EVID

очень

t'i-t:u-t

‘Это место было очень маленьким.'

быть.маленьким-ATTR-IV.SG 
Несмотря на сходство синтаксического поведения неизменяемых прилагательных и атрибутивов при связке, это сходство не может считаться достаточным для объединения неизменяемых прилагательных и атрибутивов в один класс: в роли присвязочного элемента могу выступать и существительные, и некоторые глагольные формы, а потому этот контекст не является диагностическим для определения частеречной принадлежности.

\section{3. Согласование атрибутивов с определяемой вершиной}

Атрибутивы и указательные местоимения имеют согласовательную парадигму, отличающую их от всех остальных частей речи. Как показано в таблице 2, согласовательная парадигма атрибутива имеет немаркированный род I и маркированный род IV, в то время как в согласовательной парадигме глагола род I является маркированным, а род IV - немаркированным. Примеры (28)-(32) показывают все морфологические возможности согласования атрибутива.

(28) mu-t:u

быть.красивым-ATTR.ISG

'красивый мужчина'

(29) mu-t:u-r

быть.красивым-ATTR-II.SG

'красивая женщина'

(30) mu-t:u-b

быть.красивым-ATTR-III.SG

'красивая лошадь'

(31) mu-t:u-t

быть.красивым-ATTR-IV.SG

'красивый дом'

(32) mu-t:-ib

быть.красивым-ATTR-PL

'красивые дети' bošor

мужчина(I)[SG.ABS]

1:onnol

женщина(II)[SG.ABS]

no ${ }^{\complement \breve{S}}$

лошадь(III)[SG.ABS]

nokl'

дом(IV)[SG.ABS]

lo-bur

ребенок(IV)-PL.ABS

Важным отличием атрибутива от всех остальных частей речи является возможность иметь более одной позиции согласования и более одного контролера, как показано в примере (33):

(33) $\mathrm{k}^{\mathrm{w} a} \mathrm{a}<\mathrm{r}>\mathrm{s} u-\mathrm{t}: \mathrm{u}-\mathrm{b}$ zabar

случаться<II.SG〉PFV-ATTR-III.SG

история(III)[SG.ABS]

b-ate

III.SG-пускать.IMP

'Расскажи нам, что с тобой случилось.' 
В этом примере атрибутив $k^{w} a r s ̌ u t: u b$ 'случившееся' имеет согласовательную инфиксальную позицию, контролируемую единственным аргументом непереходного глагола 'случаться (с кем)'. Наличие инфикса $\langle r\rangle$ указывает на женский род референта нулевого объекта глагола 'случаться'. Суффиксальный же маркер согласования на атрибутиве суффикс - $b$ (III.SG) контролируется определяемым существительным $\chi a b a r$ ‘история, рассказ', принадлежащим к роду III.

Неизменяемые прилагательные не имеют возможности согласования:

(34) dalu

сумасшедший

'дикая история'

(35) *dalu-b

сумасшедший

*‘дикая история’

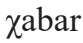

история(III)[SG.ABS]

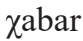

история(III)[SG.ABS]

\section{4. Падежное маркирование в безвершинном употреблении}

Атрибутивы отличаются от неизменяемых прилагательных и своим поведением в безвершинной конструкции. В этой позиции атрибутив может присоединять падежные окончания существительных. Так, в примере (36) атрибутив t:a'mat:uтmun ‘богатый’ маркирован генитивом:

(36) $1: a^{\varsigma}$ ma-t:u-m-mu-n

быть.богатым-ATTR-I.SG-OBL.SG-GEN b-ikir

III.SG-бЫTь.ITER

'У богатого почета больше бывало.' [Кибрик и др., 1977, с. 9] q'imat

уважение(III)[SG.ABS]

В примере (37) атрибутив, маркированный дативом, вместе с указательным местоимением jar обозначают адресата глагола $a \chi^{\varsigma}$ ‘ быть достаточным':

(37) ja-r do:'zu-r-mi-s

этоT-II.SG быть.большим.ATTR-II.SG-OBL.SG-DAT

os $\mathrm{a} \chi^{\varsigma}$

один[IV.SG] быть достаточным

'Старшей (дочери) одной (конфеты) хватит (досл.: этой большой одной хватит).'

В отличие от атрибутивов, неизменяемые прилагательные не могут употребляться без вершины, что демонстрируют примеры (38) и (39). 
(38) zari

$$
\operatorname{arsi}
$$

dalu

1sG.ERG деньги(IV)[SG.ABS]

сумасшедший

bošor-mi-s

kło

мужчина(I)-SG.OBL-DAT

[IV.SG]давать.PFV

'Я дал деньги сумасшедшему мужчине.'
(39) ? zari
arsi
dalu
kło
1SG.ERG деньги(IV)[SG.ABS]
сумасшедший
[IV.SG]давать.PFV
? 'Я дал деньги сумасшедшему.'

Насколько мне известно, неизменяемые прилагательные не принимают падежных окончаний: в текстах не встречается примеров безвершинного употребления неизменяемых прилагательных, а при элицитации говорящие затрудняются дать оценку грамматичности примеров типа (39). В целом, такое поведение неизменяемых прилагательных указывает на то, что они принадлежат к другому классу, нежели атрибутивы.

\section{4. Внутренние морфосинтаксические свойства атрибутивов}

Атрибутивы в арчинском языке могут быть образованы от любой части речи. Эта универсальность производящей базы типологически выделяет арчинский атрибутив срели других «смешанных» категорий. Например, причастия стандартно совмещают в себе свойства прилагательных и глаголов, проприетивы в тунгусских языках объединяют в себе свойства существительных и прилагательных [Nikolaeva, 2008], отглагольные номинализации имеют свойства существительных и глаголов [Koptjevskaja-Tamm, 1993], но ситуация, когда стратегия совмещения свойств разных частей речи в одном слове распространяется на все части речи, является типологически редкой. Арчинский же атрибутив может быть образован от глагола (разд. 4.1), наречия (разд. 4.2), послелога (разд. 4.3), существительного (разд. 4.4) и связанной основы (разд. 4.5).

\section{1. Атрибутивы, образованные от глаголов}

Отглагольный атрибутив образуется от видовой основы глагола, а не от глагольной словоформы. При этом сохраняется возможность выражать аспектуальные характеристики (разд. 4.1.1), позицию согласования (разд. 4.1.2) и падежное маркирование аргументов (разд. 4.1.3).

\subsection{1. Видовые основы глагола и атрибутив}

Глаголы в арчинском языке делятся на два класса в зависимости от количества видовых основ. У динамического глагола выделяется четыре видовые основы (основа перфектива, основа имперфектива, 
основа финалиса и основа потенциалиса). Таблица 3 показывает видовые основы нескольких динамических глаголов. Все они представлены в согласовательной форме IV.SG, с нулевым показателем согласования.

Таблица 3

\section{Видовые основы динамических глаголов}

[Кибрик, 1977, с. 65-66]

\begin{tabular}{|c|c|c|c|c|}
\hline & PFV & IPFV & FIN & POT \\
\hline ‘спать' & $a \chi u$ & arqa-r & $a \chi a-s$ & $a \chi u-q i$ \\
\hline ‘делить' & $q^{\prime} \varsigma_{O}$ & $q^{\prime \varsigma} a-r$ & $q^{\prime \varsigma} a-s$ & $q^{\prime}{ }^{\varsigma} O-q i$ \\
\hline ‘замерзать' & $q a$ & $q e\langle r\rangle q i-r$ & $q e-s$ & $q a-q i$ \\
\hline ‘бить’ & $d a \chi d i$ & $d a\langle r\rangle \chi i-r$ & daxi-s & da $d i-q i$ \\
\hline
\end{tabular}

У стативного же глагола - только одна, имперфективная, основа. Стативные глаголы в основном обозначают свойства, а не действия: $a \chi$ 'быть далеким', hiba 'быть хорошим', ja't'an 'быть красным'. Атрибутивы образуются как от стативных (40), так и от динамических глаголов (41):

(40) t'i-t:u-t

быть.маленьким-ATTR-IV.SG

'маленький дом'

(41) kło-t:-ib

[IV.PL]давать.PFV-ATTR-PL

'отданные вещи' nok1'

дом(IV)[SG.ABS]

q'ij

вещи(IV)[PL.ABS]

Поскольку стативный глагол имеет только одну видовую основу, от него образуется только один атрибутив: aұdut 'далекий', hibat:ut 'хороший', ja't'annut 'красный', $k t$ 'annut 'любимый', sinit:ut 'знакомый'. Динамический же глагол образует атрибутивы от каждой видовой основы. Чтобы представлять себе размер парадигмы атрибутивных форм динамического глагола, необходимо учесть видовые основы, согласовательные формы самого глагола (выраженные префиксами и инфиксами, см. табл. 1), и согласовательные формы атрибутива (показатели, следующие за суффиксом -t:u).

\subsection{2. Согласование отглагольных атрибутивов}

Все атрибутивы согласуются «внешне» с вершиной определяемой именной группы или с абсолютивом клаузы в присвязочной позиции. Отглагольные атрибутивы могут еще согласовываться «внутренне» с абсолютивным аргументом производящего глагола в случае, когда 
глагол имеет позицию согласования. Около 3,7\% стативных глаголов и около 88\% простых динамических глаголов имеют эту позицию. Когда атрибутив образуется от согласуемого глагола, глагольная основа согласуется с абсолютивом, используя префиксы и инфиксы (см. табл. 1), а атрибутив - со своей вершиной, используя суффиксальные маркеры согласования (см. табл. 2). В результате получается словоформа с двумя согласовательными позициями.

В табл. 4 показаны некоторые атрибутивные формы от непереходного динамического глагола aұas 'спать', в том числе случай, когда абсолютив атрибутивизированного глагола кореферентен существительному, определяемому атрибутивом.

Таблица 4

Образование атрибутивов от динамического глагола aұas 'спать'

\begin{tabular}{|c|c|c|c|c|}
\hline $\begin{array}{c}\text { Род } \\
\text { контролера }\end{array}$ & PFV & IPFV & FIN & POT \\
\hline I.SG & $a\langle w\rangle \chi u-t: u$ & $w$-arza-r-t:u & $w-a \chi a-s-t: u$ & $a\langle w\rangle \chi u-q i-t: u$ \\
\hline II.SG & $a\langle r\rangle \chi u-t: u-r$ & 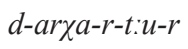 & $d-a \chi a-s-t: u-r$ & $a\langle r\rangle \chi u-q i-t: u-r$ \\
\hline III.SG & $a<b>\chi u-t: u-b$ & $b-a r \chi a-r-t: u-b$ & $b-a \chi a-s-t: u-b$ & $a\langle b>\chi u-q i-t: u-b$ \\
\hline IV.SG & $a \chi u-t: u-t$ & arqa-r-t:u-t & $a \chi a-s-t: u-t$ & $a \chi u-q i-t: u-t$ \\
\hline I/II.PL & $a<b>\chi u-t:-i b$ & $b$-arqa-r-t:ib & $b-a \chi a-s-t:-i b$ & $a<b>\chi u-q i-t:-i b$ \\
\hline III/IV.PL & $a \chi u-t:-i b$ & $a r \chi a-r-t:-i b$ & $a \chi a-s-t:-i b$ & $a \chi u-q i-t:-i b$ \\
\hline Перевод & ‘спящий’ & $\begin{array}{c}\text { 'тот, кто } \\
\text { много спит' }\end{array}$ & $\begin{array}{c}\text { ‘тот, кто } \\
\text { должен спать' }\end{array}$ & $\begin{array}{c}\text { 'тот, кто } \\
\text { будет спать' }\end{array}$ \\
\hline
\end{tabular}

В ситуации, когда абсолютив производящего глагола некореферентен определяемой вершине, 'внешнее' и 'внутреннее' согласование атрибутива будет принимать разные значения рода и числа. Так, атрибутив

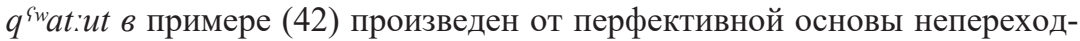
ного глагола 'приходить', но определяемое существительное не является подлежащим этого глагола, и в результате атрибутив согласуется по роду I со своим абсолютивным аргументом tuw 'он' и по роду IV со своей вершиной, существительным в инессиве sa९anna 'время'.

(42) tu-W

TOT-I.SG[ABS] I.SG.приходить.PFV-ATTR-IV.SG

saSanna

‘...когда он подойдет (досл.: во время его прихода)'

время(IV).IN 
В примере (43) атрибутив $k$ 'waqit:ut 'умирающий (тот, кто скоро умрет)' произведен от основы потенциалиса глагола $k$ 'as 'умирать' и модифицирует существительное в инэссиве, не входящее в аргументную структуру глагола.

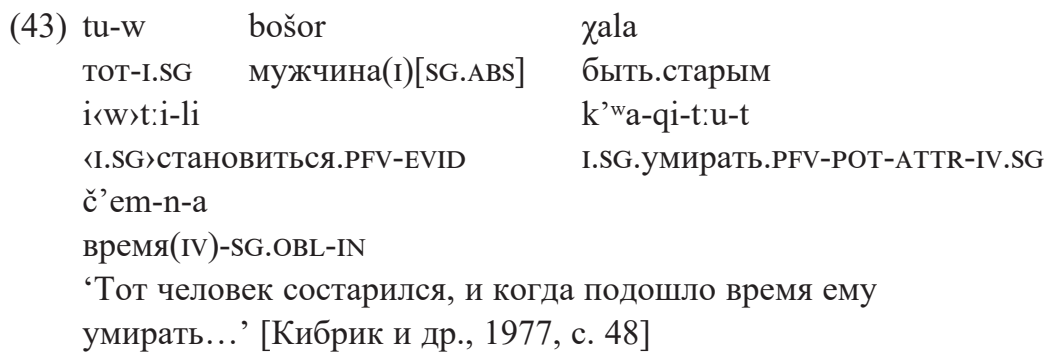

Атрибутивы, образованные от переходных глаголов, тоже могут иметь внутренний абсолютив, кореферентный определяемой вершине. Тогда обе согласовательные позиции атрибутива - внутренняя и внешняя - принимают одно и то же значение рода и числа. Так обстоят дела в примере (44), где (невыраженный) абсолютив глагола ұо 'находить' кореферентен определяемой вершине ћawanu 'животное' и атрибутив имеет два показателя III.SG - префиксальный и инфиксальный:

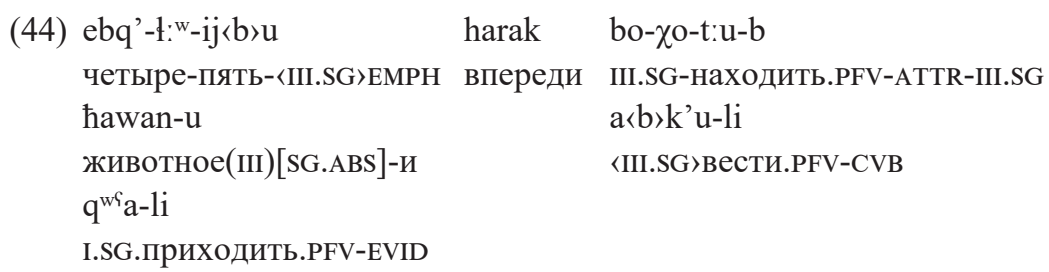

'Он пришел, ведя впереди себя четыре-пять найденных овец (досл.: животных).’ [Там же, с. 15]

Если абсолютивный аргумент переходного глагола некореферентен определяемой вершине, атрибутив имеет разные согласовательные показатели с разными контролерами. В примере (45) глагольная основа атрибутива ak:urt:ur 'виденная' согласуется по роду IV со своим абсолютивом - вершиной именной группы c'abu-t:u-t t:an 'выпитая вода'. В то же время, суффиксальная позиция согласования атрибутива контролируется (невыраженной) вершиной lo 'девушка': 


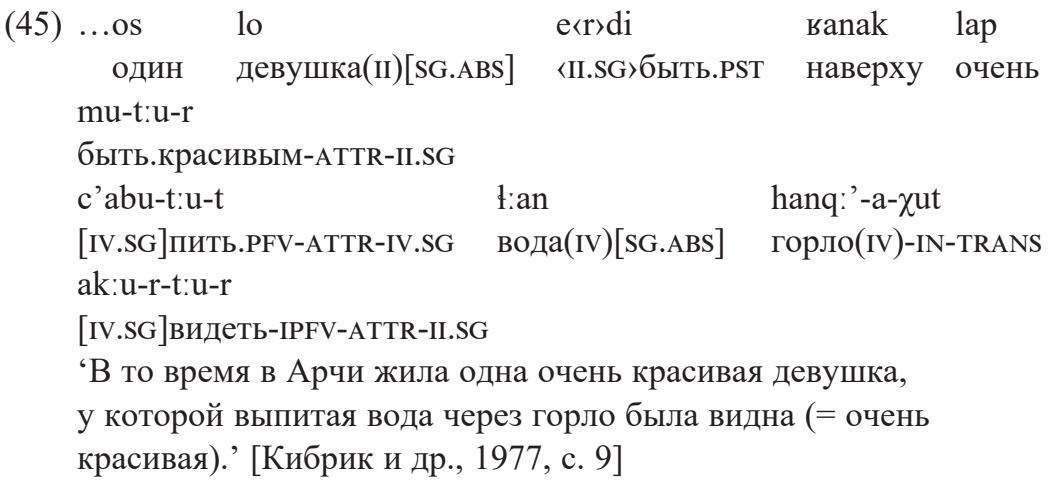

Таким образом, атрибутивы, образованные как от переходных, так и от непереходных глаголов, могут иметь разных контролеров согласования для разных позиций в одной словоформе.

\subsection{3. Управление падежом \\ аргумента атрибутивизированного глагола}

Атрибутивы, образованные от глагола, сохраняют способность управлять падежами глагольных аргументов. Так, в примере (46) атрибутивная группа $e z$ ak:ut:ut 'виденное мной' модифицирует существительное q'waridkul 'горе'. Глагол ak:as 'видеть' требует экспериенцера в дативе. Также ведет себя и атрибутив от этого глагола, определяющий форму местоимения $e z$ 'я'.

(46) ez

[IV.SG]1SG.DAT et:i-t'u ak:u-t:u-t

[IV.SG]видеть-ATTR-IV.SG q'waridkul rope(IV)[SG.ABS]

[IV.SG]становиться.PFV-NEG

'...c тех пор горя у меня не было (досл.: горя, мной виденного, не стало).'

\subsection{4. Отглагольные атрибутивы и причастия}

Если бы глагол был единственной частью речи, от которой образуется атрибутив, последний можно было бы считать причастием. В этом случае арчинский язык не отличался бы от других дагестанских (и не только) языков, где отглагольные формы, служащие определением к существительному, сохраняют глагольные свойства. Арчинский атрибутив демонстрирует все свойства типичного дагестанского причастия, но отличается тем, что может образовываться не только от глагола, но и от других частей речи, о чем речь ниже. 


\section{2. Атрибутивы, образованные от наречий}

Атибутив č'ollijxut:ub 'внешний, передний, тот, что снаружи', пред-

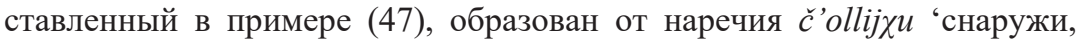
на улице'. В этом примере он служит определением к существительному dotum 'хлев' (употребленному в инэссиве) и согласуется с определяемым существительным по роду и числу:

\begin{tabular}{|c|c|c|}
\hline 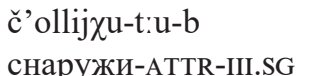 & $\begin{array}{l}\text { dołuma } \\
\text { хлев(III).IN }\end{array}$ & $\begin{array}{l}\text { aq:'u } \\
{[1 \text { PL]оставлять.PFV }}\end{array}$ \\
\hline
\end{tabular}

\section{3. Атрибутивы, образованные от послелогов}

Как и в случае с отглагольными атрибутивами, атрибутивы, образованные от послелогов, сохраняют морфосинтаксические свойства производящего слова. Для послелогов это управление определенным падежом. Например, атрибутив ұarakdut 'тот, что позади' в примере (48) образован от послелога ұarak 'позади'. Этот послелог управляет дативом, и существительное iškollis 'школа' в этом примере, хотя за ней следует не послелог, а атрибутив, имеет форму датива. Атрибутив же в свою очередь согласуется со своей вершиной, именной группой nokt' 'дом'.

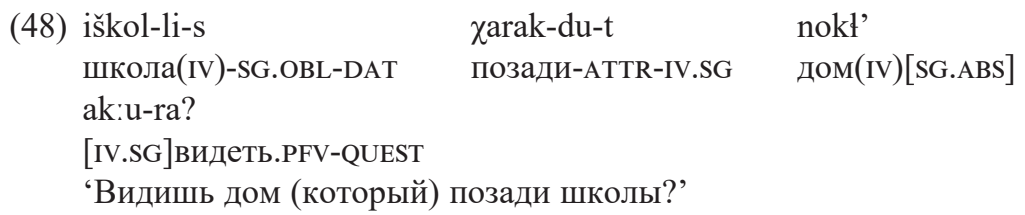

\section{4. Атрибутивы, образованные от существительных}

В отличие от отглагольных атрибутивов, атрибутивы от существительных образуются от падежных форм, т.е. не от основ, а от полных слововорфм. Все падежи, кроме эргативного, могут образовывать атрибутив.

В табл. 5 содержатся примеры образования атрибутивов от нелокативных падежных форм. В табл. 6 представлены примеры атрибутивов, образованных от локативных форм существительного. Данные формы невозможно точно перевести на русский язык, поэтому они переведены как относительные обороты.

Атрибутивы, образованные от падежных форм существительного, сохраняют исходную падежную семантику, как показано в примере (49), где дативная форма существительного 'сестра' означает, что ее референт является адресатом: 
(49) doš-mi-s-du-t

сестра(II)-SG.OBL-DAT-ATTR-IV.SG

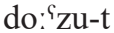

быть.большим.ATTR-IV.SG pet:uq'

сундук(IV)[SG.ABS]

i

[IV.SG]быть.PRS

'Сестрин сундук большой (досл.: тот, что для сестры).'

Таблица 5

Падежные формы, от которых может образовываться атрибутив

\begin{tabular}{|c|c|c|}
\hline & Имя & Атрибутив \\
\hline ГЕНИТИВ & $\begin{array}{l}\text { šamil-li-n } \\
\text { Шамиль-OBL.SG-GEN }\end{array}$ & 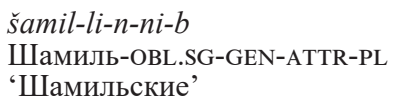 \\
\hline ДАТИВ & $\begin{array}{l}d o s ̌-m i-s \\
\text { сестра-OBL.SG-DAT }\end{array}$ & $\begin{array}{l}d o s ̌-m i-s-d u-t \\
\text { сестра-OBL.SG-DAT-IV.SG } \\
\text { 'то, что для сестры' }\end{array}$ \\
\hline КОМПАРАТИВ & $\begin{array}{l}\chi^{\varsigma} \text { ini- } \chi u r \\
\text { корова-СMPR }\end{array}$ & 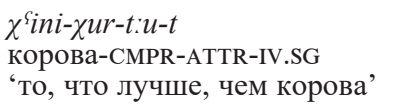 \\
\hline КОМИТАТИв & $\begin{array}{l}\text { wa-t:u } \\
\text { 2sG-СомIт }\end{array}$ & $\begin{array}{l}\text { wa-t:u-t:-ib } \\
\text { 'те, кто был с тобой' }\end{array}$ \\
\hline
\end{tabular}

Абсолютив также может служить производной основой для атрибутива, однако употребление атрибутивов от абсолютива ограничено: в текстах зафиксировано только безвершинное употребление таких абсолютивов (см. пункт 3.4), как правило, это топикализованные аргументы. Так, атрибутив lot:u в примере (50), образованный от существителльного lo 'парень', употреблен без вершины:

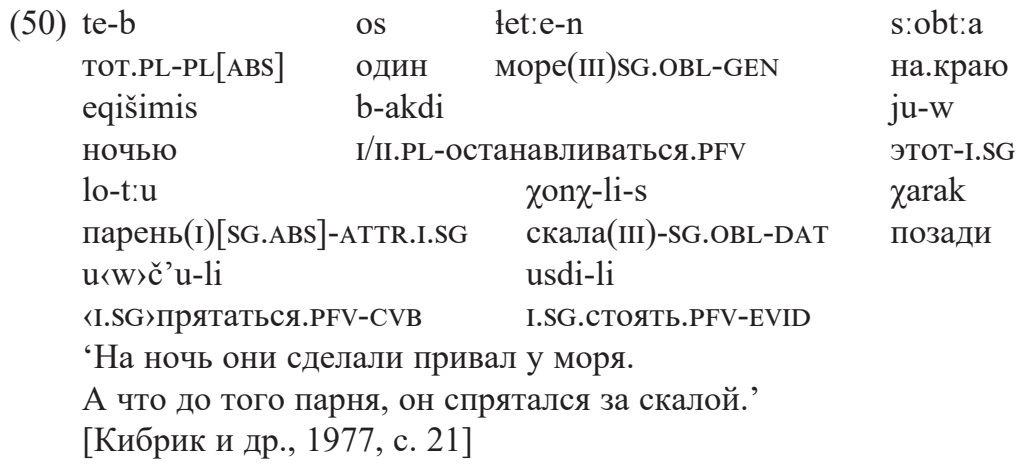


$\underset{\substack{n \\ 0}}{\stackrel{0}{3}}$

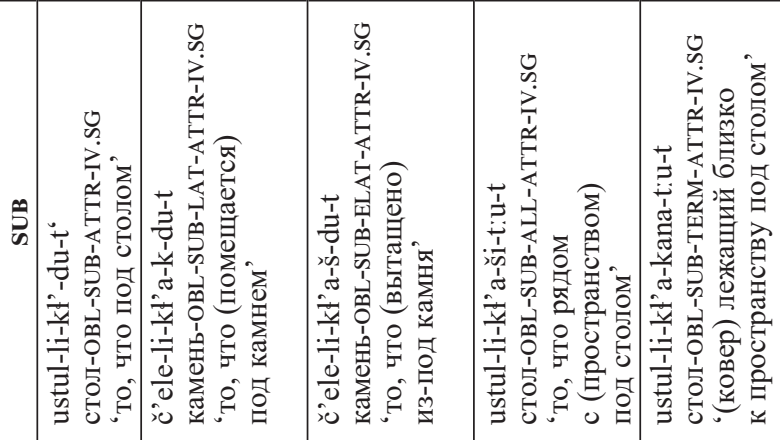

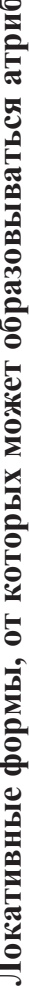

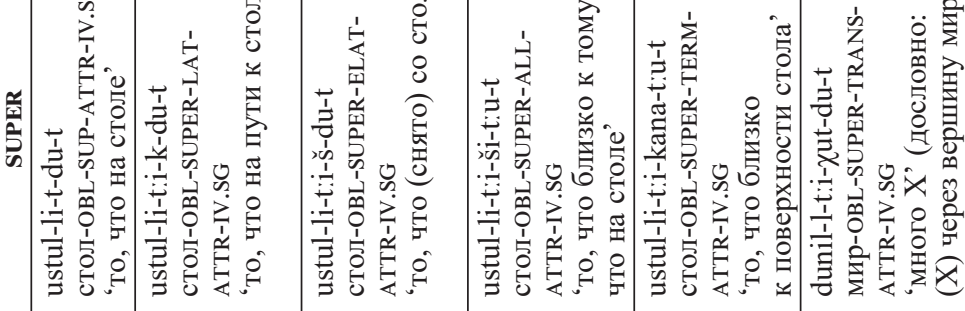

(2)



(1)

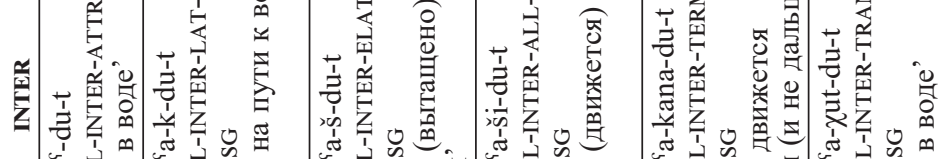

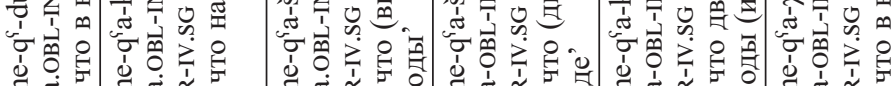

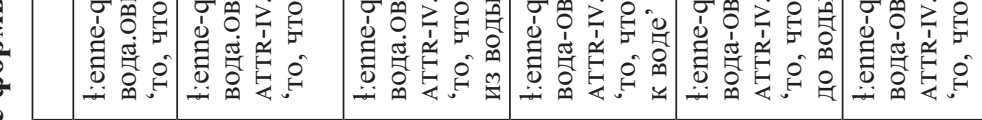

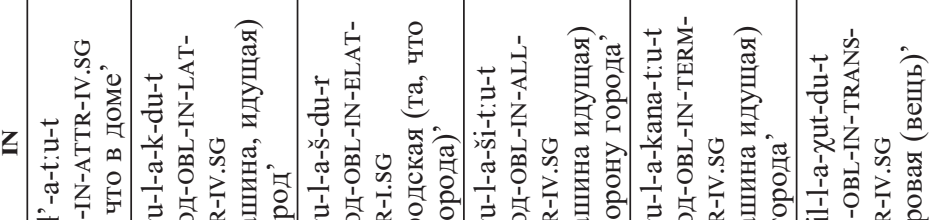
这 T.

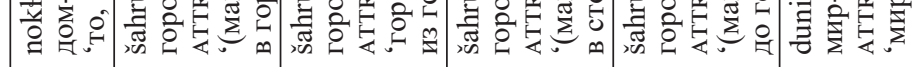


Безвершинный атрибутив может также присоединять падежные окончания. В данном случае можно говорить о «внутреннем» и «внешнем» падежном маркировании. В примере (51) атрибутив došmisdummis 'сестринский, тот, что предназначен для сестры' присоединяет окончание дательного падежа дважды: одно окончание - перед атрибутивным суффиксом - $d u$ и одно - после него. Первое окончание выражает бенефактивную семантику (сундук для сестры), а второе окончание обусловлено послелогом $\chi a r a k$ 'позади':

(51) doš-mi-s-du-m-mi-s ұarak сестра(II)-SG.OBL-DAT-ATTR-IV.SG-SG.OBL-DAT позади is

[IV.SG]1SG.GEN [IV.SG]быть.PRS

'Мой (сундук с приданым) позади сестринского (того, что для сестры).'

\section{5. Атрибутивы, образованные от связанных основ}

Некоторые атрибутивы образуются от основ, которые не употребляются без атрибутивного суффикса. В этих словах можно морфологически выделить атрибутивный суффикс, но основу сложно отнести к какой-либо части речи, поскольку эти слова употребляются в современном арчинском языке только с атрибутивным суффиксом. Примеры некоторых связанных основ приведены в (52).

(52) diribašdu 'шустрый'

pulannи 'некий, такой-то'

qarcinnи 'ленивый'

saxawat:u 'щедрый’

terst:u 'упрямый'

zurbat:u сильный, крепкий'

Simarat:ut 'очень красивый'

Атрибутивы от связанных основ синтаксически ведут себя так же, как и обычные атрибутивы:

(53) ters-t:u-r

1:onnol

oq-li-t

упрямый-ATTR-II.SG

женщина(II)[SG.ABS]

свадьба(IV)-SG.OBL-SUP

d-e:'-t'u

II.SG-ИДТИ.POT-NEG

'Упрямая женщина не идет на свадьбу.' 
(54)
pulan-n-ib
bokl'
e $<b>$ di-li
какой-TO-ATTR-ATTR.PL
люди(I/II)[PL.ABS]
«I/II.PL〉быть.PST-EVID
ja-t
duxriq ${ }^{\varsigma}$
этоT-IV.SG
деревня(IV).SG.INTER.ESS
'Такие-то люди жили в этой деревне.'
(традиционный зачин истории)

Скорее всего, этот тип представляет собой атрибутивы от утраченных стативных глаголов. В пользу этого предположения говорит то, что при элицитации говорящие признают грамматичными конвербные формы этих слов, например, tersši 'будучи упрямым', pulanši 'будучи таким-то', но в текстах встречаются только атрибутивные формы. Поскольку стативные глаголы редко употребляются в неатрибутивной форме, нетрудно представить себе сценарий диахрониченского развития, когда от полной парадигмы стативного глагола остается только атрибутив.

\section{5. Заключение}

Атрибутив в арчинском языке представляет собой необычную категорию. С одной стороны, у него имеются четкие морфосинтаксические характеристики, позволяющие выделить его в отдельный класс: употребление в качестве определения к существительному и уникальная согласовательная парадигма. С другой стороны, арчинский атрибутив представляет собой редкий случай «смешанной» категории, поскольку он образуется от всех частей речи, сохраняя при этом морфосинтаксические свойства производящего слова. Среди языков нахско-дагестанской семьи, кроме арчинского, только в андийском языке зафиксирован атрибутив, образующийся от всех частей речи, но, в отличие от арчинского, андийский атрибутив не имеет возможности согласования [Майсак, 2018].

Арчинский атрибутив проблематичен и с точки зрения разделения словообразования и словоизменения. Продуктивность и семантическая регулярность атрибутива не позволяет отнести его к словообразовательной категории; кроме того, в атрибутивном классе нет непроизводных лексем. Морфологическая структура арчинского атрибутива говорит в пользу того, что словоизменительные процессы могут применяться как до, так и после транспозиции. 


\section{Библиографический список / References}

Архипов и др., 2008 - Арчинский язык / Архипов А.В., Даниэль М.А., Кибрик А.Е., Чумакина М.Э. // Малые языки и традиции: существование на грани / А.Е. Кибрик (ред.). М., 2008. C. 192-231. [Arhipov A.V., Daniel' M.A., Kibrik A.E., Chumakina M.E. Archi. Malye yazyki i traditsii: sushchestvovanie na grani. Kibrik A.E. (ed.). Moscow, 2008. Pp. 192-231.]

Гращенков, 2018 - Гращенков П.В. Грамматика прилагательного. Типология адьективности и атрибутивности. М., 2018. [Grashchenkov P.V. Grammatika prilagatel'nogo. Tipologiya ad'ektivnosti i atributivnosti [The grammar of adjectives. The typology of adjectival categories and attributivization]. Moscow, 2018.]

Кибрик, 1977 - Кибрик А.Е. Опыт структурного описания арчинского языка. T. II: Таксономическая грамматика. М., 1977. [Kibrik A.E. Opyt strukturnogo opisaniya archinskogo yazyka [Structural description of the Archi language]. Vol. II: Taxonomic grammar. Moscow, 1977.]

Кибрик и др., 1977 - Арчинский язык. Тексты и словари / Кибрик А.Е., Кодзасов С.В., Оловянникова И.П., Самедов Д.С. М., 1977. [Kibrik A.E., Kodzasov S.V., Olovyannikova I.P., Samedov D.S. Archinskiy yazyk. Teksty i slovari [Archi. Texts and dictionaries]. Moscow, 1977.]

Майсак, 2018 - Майсак Т.А. Атрибутивные показатели в андийском языке: клитики или аффиксы? // Acta Linguistica Petropolitana. Труды Института лингвистических исследований. 2018 (в печати). [Maysak T.A. Attributives in Andi: Clitics or affixes? Acta Linguistica Petropolitana. 2018. In print.]

Bond et al., 2016 - Archi: Complexities of agreement in cross-theoretical perspective. Bond O., Corbett G.G., Chumakina M., Brown D. (eds.). Oxford, 2016.

Corbett, 1991 - Corbett G.G. Gender. Oxford, 1991.

Chumakina, Corbett, 2015 - Chumakina M., Corbett G.G. Gender number marking in Archi: Small is complex. Understanding and measuring morphological complexity. Baerman M., Brown D., Corbett G.G. (eds). Oxford, 2015. Pp. 93-116.

Haspelmath, 1996 - Haspelmath M. Word-class-changing inflection and morphological theory. Yearbook of Morphology 1995. Booij G., van Marle J. (eds.). Dordrecht, 1996. Pp. 43-66.

Koptjevskaja-Tamm, 1993 - Koptjevskaja-Tamm M. Nominalizations. London, 1993.

Nikolaeva, 2008 - Nikolaeva I. Between nouns and adjectives: A constructional view. Lingua. 2008. Vol. 118. Pp. 969-996.

Статья поступила в редакцию 15.09.2018

The article was received on 15.09.2018

Чумакина Марина Эдуардовна - кандидат филологических наук; научный сотрудник Суррейской морфологической группы факультета литературы и лингвистики, Университет графства Суррей, г. Гилфорд, Великобритания

Chumakina Marina E. - PhD in Linguistics; Research Fellow at the Surrey Morphology Group of School of Literature and Languages, University of Surrey, Guildford, United Kingdom

E-mail: M.Chumakina@surrey.ac.uk 